\title{
Is There a Global Carbonate Layer in the Oceanic Mantle?
}

\author{
TAHAR HAMMOUDA ${ }^{1}$, GEETH MANTHILAKE ${ }^{2}$, DR. \\ PHILIPPE GONCALVES ${ }^{3}$, JULIEN CHANTEL ${ }^{4}$, JÉRÉMY \\ GUIGNARD $^{5}$, WILSON CRICHTON ${ }^{6}$ AND FABRICE \\ GAILLARD $^{7}$ \\ ${ }^{1}$ Université Clermont Auvergne \\ ${ }^{2}$ Universite Clermont Auvergne \\ ${ }^{3}$ Université de Bourgogne Franche-Comté \\ ${ }^{4}$ Université Lille \\ ${ }^{5}$ Université de Nantes \\ ${ }^{6} \mathrm{ESRF}$ \\ ${ }^{7}$ ISTO - CNRS
}

Presenting Author: tahar.hammouda@uca.fr

Continuous $\mathrm{CO}_{2}$ degassing at volcanic centers (arcs, midocean ridges, intraplate) is balanced by recycling at subduction zones, where sediment-bearing altered oceanic plates return to the mantle. Previous studies have modeled carbonate budget in the subduction factory by experimental (as summarized in [1]) or thermodynamic approach [2,3]. Because the detailed carbon transfer mechanisms have seldom been studied, we have combined high-pressure experiments with synchrotron radiation in order to explore the outcome of having $\mathrm{CO}_{2}$-rich fluids at the slab-mantle interface. By studying a model (Fe-free) system, we were able to reproduce the pressure-temperature conditions of carbon delivery and reaction and to continuously monitor the steps of the phase assemblage modifications using in situ x-ray diffraction.

Carbonates break down at $2.25 \mathrm{GPa}$ and $1100{ }^{\circ} \mathrm{C}$, by reaction with silicates (decarbonation). (In the model, Fe-free system, all temperatures are shifted by ca. $>200{ }^{\circ} \mathrm{C}$ compared to the natural conditions.) The released $\mathrm{CO}_{2}$ is trapped at grain boundaries and remains available for further reaction. Further heating to $1300^{\circ} \mathrm{C}$ yields no change and it is only after near-isothermal compression above $3 \mathrm{GPa}$ that $\mathrm{CO}_{2}$-assisted melting occurs in what corresponds to the mantle wedge. The observed carbonate melt formation in the wedge may be a way for continuous carbon introduction and dissemination away from the wedge because of the strong infiltration power of carbonatite melts [4]. Carbon presence has been discussed in a variety of contexts, under the oceanic lithosphere (hotspots, petit spots, and fossil ridges). We suggest the presence of a global carbon-rich layer under the oceanic lithosphere that is steadily fueled by subduction processes. This layer can be the source of mechanical weakening of the lithosphere-asthenosphere boundary under the oceans. Therefore, the reported carbon-induced compression melting may be a key mechanism of modern-style plate tectonics.

[1] Hammouda, T, Keshav, S (2015) Chemical Geology, 418, $171-188$

[2] Molina, J F, Poli, S (2000) Earth Planet. Sci. Lett. 176: 295-310

[3] Gorman, PJ., Kerrick, D.M, Conolly, JAD (2006) Geochemistry, Geophysics, Geosystems, 7, Q04007.

[4] Hammouda, T, Laporte, D (2000) Geology, 28, 283-285. 